\title{
Viscoelastic properties of elastomeric impression materials: polysulphide, silicone and polyether rubbers
}

\author{
L. G. T O L L E Y and R. G. C R A I G University of Michigan School of \\ Dentistry Ann Arbor, Michigan
}

\begin{abstract}
Summary
Creep compliance measurements were shown to be effective in characterizing the elastic, retarded elastic, and viscous properties of polysulphide, silicone, and polyether impression materials. The test is particularly valuable in that the creep compliance was independent of load, allowing the mechanical properties to be represented by a single total creep compliance curve which can be used to determine the various creep components. The total recovered compliance was shown to be independent of time provided the polymerization had progressed sufficiently before testing was done. The retarded elastic and viscous compliances contributed proportionally to the total creep compliance and thus did not affect the rankings of materials. The viscous compliance of polysulphide A decreased enough after $1 \mathrm{~h}$ so that the creep compliance of $\mathrm{A}$ and $\mathrm{D}$ were not different. The creep compliance measurements showed that the polysulphide materials were the most viscoelastic followed by silicone and polyether impression materials. The polyether was the most nearly ideal elastic material but it had a flexibility comparable to heavy body polysulphide. Of particular interest was the observation that polyether with thinner in ratios up to $1: 1$ by length had no practical effect on the viscoelastic properties.
\end{abstract}

\section{Introduction}

The creep compliance and recovery of selected elastic impression materials after application and removal of static loads was reported by Goldberg (1974). The creep compliance test allows a separation and evaluation of the time-dependent and time independent responses of elastic impression materials under load and provides a better understanding of their mechanical properties.

The creep compliance is the time-dependent relationship of the strain to stress ratio of a material under load. The creep compliance, $J(t)$, can be subdivided into three components as reviewed by Oglesby (1972) and can be expressed as:

$$
\mathrm{J}(\mathrm{t})=\mathrm{J}_{0}+\mathrm{J}_{\mathrm{R}}+\mathrm{t} / \eta
$$

where $\mathrm{J}_{0}$ is the instantaneous elastic compliance, $\mathrm{J}_{\mathrm{R}}$ is the retarded elastic component, and $t / \eta$ is the viscous component or flow which is directly proportional to time, $t$,

Correspondence: Dr R. G. Craig, Department of Dental Materials, University of Michigan, School of Dentistry, Ann Arbor, Michigan 48109, U.S.A. 
and inversely proportional to the viscosity, $\eta$. A plot of $J(t)$ vs $t$ is shown in Fig. 1 which also indicates how $J_{0}, J_{R}$, and $t / \eta$ can be separated. The retarded elastic component, $J_{R}$, can be determined by linearily extrapolating the curve to zero time, and the viscous component can be found from the time-dependent slope of the linear portion of the compliance curve. The recovery can be taken to be proportional to the total elastic compliance $\left(J_{0}+J_{R}\right)$ if the elastomer has sufficiently polymerized and, if not, the recovery will decrease with time. The total creep compliance curve is calculated from plots of creep (deflection) vs time for various load. Since Goldberg (1974) demonstrated that the total creep compliance for elastic impression materials was independent of load a single creep compliance vs time curve is obtained for an elastomer at a given time of testing after mixing.

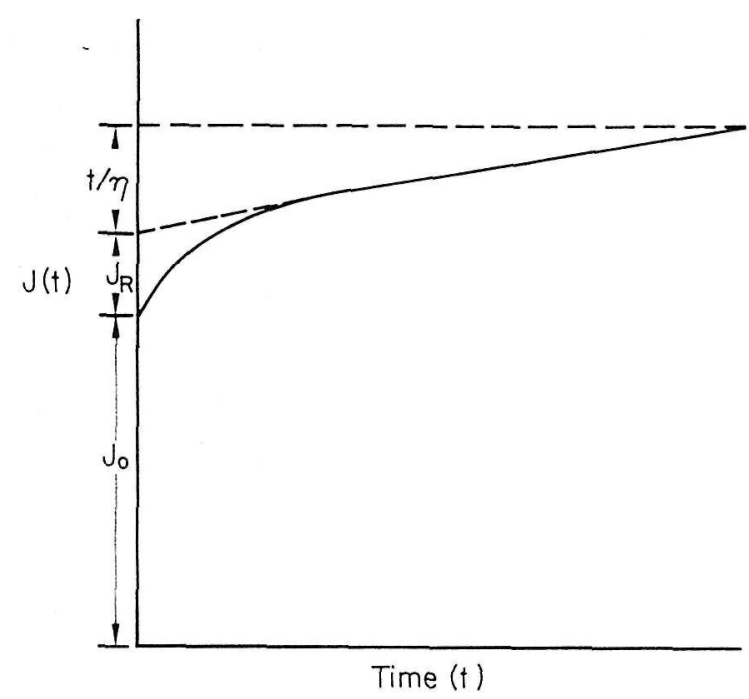

Fig. 1. Total creep compliance, $J(t)$, as a function of time illustrating elastic creep compliance, $J_{0}$, retarded elastic compliance, $J_{R}$, and the viscous compliance, $t / \eta$. $J(t)=J_{0}+J_{R}+t / \eta$.

The purpose of this study was to determine the creep compliance curves for a number of elastic impression materials (polysulphide silicone, and polyether) at different times after setting and to separate the components of the total creep compliance in order to better understand the behaviour of these materials under and after the removal of load.

\section{Materials and methods}

The polysulphides (A-D), silicone (E), and polyether $(\mathrm{F})$ included in the study are listed in Table 1 together with their type, batch number, and manufacturer. The polyether was used without thinner and in the ratio of the length of base paste to thinner of $1: 0 \cdot 25,1: 0 \cdot 5$, and $1: 1$.

The manufacturers' recommended dispensing and mixing procedures were used. Cylindrical test specimens, $19 \mathrm{~mm}$ long by $12.7 \mathrm{~mm}$ in diameter, were prepared according to American Dental Association specification no. 19 for elastomeric impression material. The mixed materials, contained in a metal mould, were placed in a $37^{\circ} \mathrm{C}$ water bath $2 \mathrm{~min}$ after mixing and remained in the bath for the minimum time recommended by the manufacturer to be left in the mouth. The setting times for the mixes of polyether with thinner were determined by the loss of tackiness to the steel rod used to determine the working time. The setting time of the undiluted 
polyether was $7 \mathrm{~min}$ and increased $1 \mathrm{~min}$ for each dilution; the working time increased from 2.5 to $4.5 \mathrm{~min}$ for the undiluted polyether to the $1: 1$ ratio of polyether to thinner.

The creep compliance test was determined on separate specimens at $1 \mathrm{~min}$ and $1 \mathrm{~h}$ after their removal from the $37^{\circ} \mathrm{C}$ water bath. A nominal stress of $17 \cdot 2 \mathrm{kPa}$ was placed on the cylindrical specimens $30 \mathrm{~s}$ before testing and at the time of testing a

Table 1. Impression materials studied

\begin{tabular}{|c|c|c|c|c|}
\hline Designation & Material & Batch no. & Manufacturer & Type \\
\hline A & Rubberjel: syringe & $\begin{array}{l}74143 B \\
74162 \mathrm{C}\end{array}$ & $\begin{array}{l}\text { L.D. Caulk Company } \\
\text { Milford, DE }\end{array}$ & Polysulphide \\
\hline B & Rubberjel: regular & $\begin{array}{l}74148 B \\
74113 C\end{array}$ & $\begin{array}{l}\text { L.D. Caulk Company } \\
\text { Milford, DE }\end{array}$ & Polysulphide \\
\hline $\mathrm{C}$ & Rubberjel: heavy body & $\begin{array}{l}74155 \mathrm{~B} \\
74158 \mathrm{C}\end{array}$ & $\begin{array}{l}\text { L.D. Caulk Company } \\
\text { Milford, DE }\end{array}$ & Polysulphide \\
\hline $\mathrm{D}$ & Image & MN003002 & $\begin{array}{l}\text { Cadco Division } \\
\text { Dento Industries, Inc. } \\
\text { Los Angeles, CA }\end{array}$ & Polysulphide \\
\hline $\mathrm{E}$ & Jelcone: regular & $\begin{array}{l}7471 \mathrm{~B} \\
7494 \mathrm{C}\end{array}$ & $\begin{array}{l}\text { L.D. Caulk Company } \\
\text { Milford, DE }\end{array}$ & Silicone \\
\hline$F_{0}$ & Polyjel & $\begin{array}{l}\text { B74163 } \\
\text { C74112 }\end{array}$ & $\begin{array}{l}\text { L.D. Caulk Company } \\
\text { Milford, DE }\end{array}$ & Polyether \\
\hline$F_{1}$ & Polyjel with thinner $1: 0 \cdot 25^{*}$ & $\begin{array}{r}\mathrm{B} 74163 \\
\mathrm{C} 74112 \\
\mathrm{~A} 024\end{array}$ & $\begin{array}{l}\text { L.D. Caulk Company } \\
\text { Milford, DE }\end{array}$ & Polyether \\
\hline $\mathrm{F}_{2}$ & Polyjel with thinner $1: 0 \cdot 5^{*}$ & $\begin{array}{r}\mathrm{B} 74163 \\
\mathrm{C} 74112 \\
\mathrm{~A} 024\end{array}$ & $\begin{array}{l}\text { L.D. Caulk Company } \\
\text { Milford, DE }\end{array}$ & Polyether \\
\hline $\mathrm{F}_{3}$ & Polyjel with thinner $1: 1^{*}$ & $\begin{array}{r}\mathrm{B} 74163 \\
\mathrm{C} 74112 \\
\mathrm{~A} 024\end{array}$ & $\begin{array}{l}\text { L.D. Caulk Company } \\
\text { Milford, DE }\end{array}$ & Polyether \\
\hline
\end{tabular}

* One length of base and catalyst each to proportional length of thinner added to mix.

major load of 0.5 or $1.0 \mathrm{~kg}$ was applied. The deflection of the sample then was measured as a function of time. The recoverable deflection was determined for each sample at $1,3,6$, or $12 \mathrm{~min}$ after the application of the major load. The recovered compliance was taken when a constant deflection with time was obtained, and these data were compared to the creep compliance to test for the extent of polymerization.

The creep compliance values were evaluated at $5 \mathrm{~s}, 1 \mathrm{~min}$, and $6 \mathrm{~min}$ using the Scheffé multiple comparison test (Guenther, 1964) and the materials were ranked statistically.

\section{Results}

The creep compliance for the 1 minute and 1 hour samples is plotted in Figs 2 and 3, respectively. The three components, $J_{0}, J_{R}$, and $\eta$ were determined graphically from these curves and the values are listed in Table 2, along with the total recovered compliance, $R_{\mathrm{T}}$. The shape of the compliance vs time curve gives a qualitative indication 


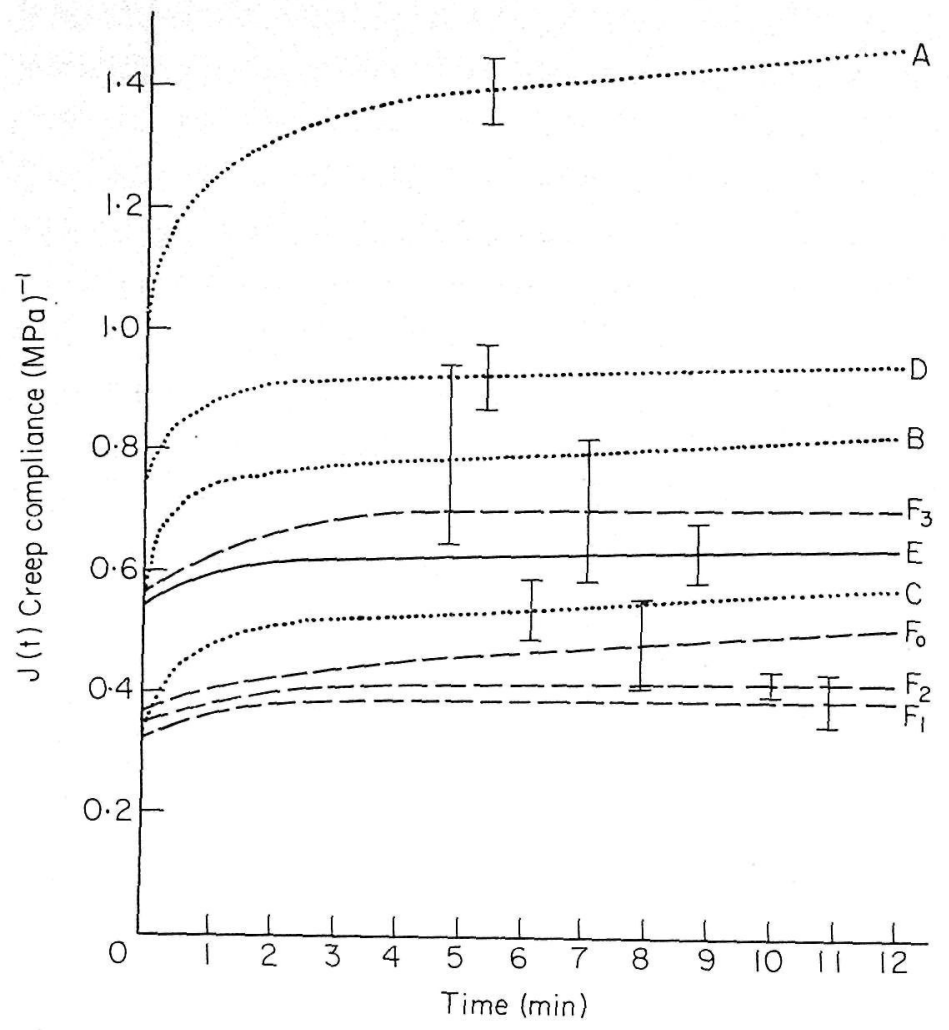

Fig. 2. Total creep compliance vs time for 1 -min samples of polysulphides $(\cdots \cdots)$, silicone ( - — and polyether (with increasing thinner $0-3,----$ ) impression materials.

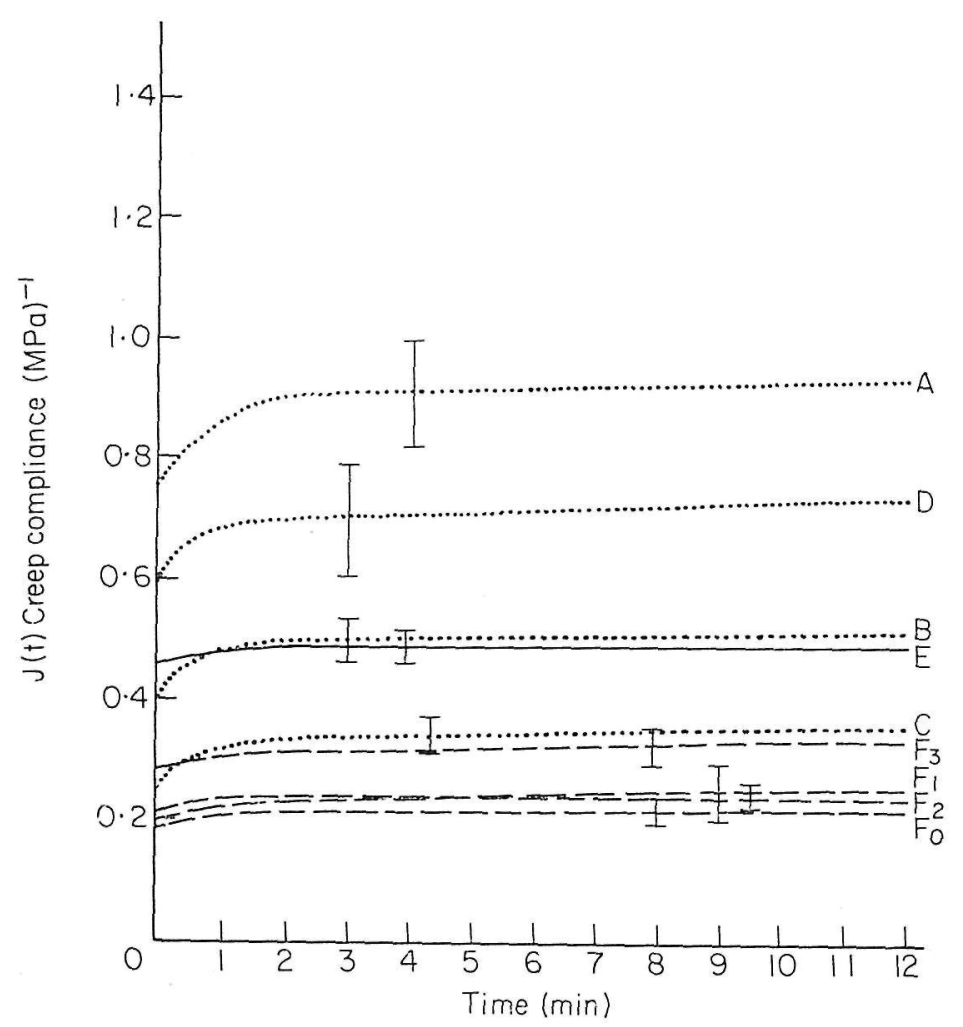

Fig. 3. Total creep compliance vs time for 1-h samples of polysulphides $(\cdots \cdots)$, silicone (___--), and polyether (with increasing thinner $0-3, \ldots--$ ) impression materials.

of the flexibility of the impression materials since those with higher creep compliance, such as material A, are substantially more flexible than materials C or F. Also, the flatness of the creep compliance vs time curve is an indication of the elastic behaviour 
of the material; for example material $\mathrm{E}$ is much nearer to perfect elasticity than material A although the latter is more flexible.

It is also apparent from Figs 2 and 3 that some materials such as the polysulphides have substantial changes in properties with time after setting compared to the silicone or polyether impression materials.

Table 2. Creep compliance and recovery

\begin{tabular}{|c|c|c|c|c|c|c|c|c|}
\hline \multirow[b]{2}{*}{ Material } & \multicolumn{4}{|c|}{1 min specimens } & \multicolumn{4}{|c|}{$1 \mathrm{~h}$ specimens } \\
\hline & $\begin{array}{r}\mathrm{J}_{0} * \\
(\mathrm{MPa})^{-1}\end{array}$ & $\begin{array}{r}\mathbf{J}_{\mathrm{R}}{ }^{*} \\
(\mathrm{MPa})^{-1}\end{array}$ & $\begin{array}{r}\mathrm{R}_{\mathrm{T}}^{\dagger} \\
(\mathrm{MPa})^{-1}\end{array}$ & $\begin{array}{r}\eta^{*} \S \\
(\mathrm{MPa}-\mathrm{sec}) \\
\times 10^{4}\end{array}$ & $\begin{array}{r}\mathrm{J}_{0}{ }^{*} \\
(\mathrm{MPa})^{-1}\end{array}$ & $\begin{array}{r}\mathbf{J}_{\mathrm{R}^{*}} \\
(\mathrm{MPa})^{-1}\end{array}$ & $\begin{array}{r}\mathbf{R}_{\mathrm{T}}^{\dagger} \\
(\mathrm{MPa})^{-1}\end{array}$ & $\begin{array}{r}\eta^{*} \S \\
(\mathrm{MPa}-\mathrm{sec}) \\
\times 10^{4}\end{array}$ \\
\hline A & $0 \cdot 99$ & $0 \cdot 35$ & $(0 \cdot 95-0 \cdot 77) \ddagger$ & 0.554 & $0 \cdot 765$ & $0 \cdot 135$ & $0.76(\cdot 012)$ & $2 \cdot 06$ \\
\hline B & $0 \cdot 57$ & $0 \cdot 19$ & $0.54(0.08)$ & $1 \cdot 03$ & $0 \cdot 41$ & $0 \cdot 08$ & $0.43(0.02)$ & $2 \cdot 40$ \\
\hline $\mathrm{C}$ & $0 \cdot 34$ & $0 \cdot 27$ & $0 \cdot 32(0 \cdot 03)$ & $2 \cdot 40$ & $0 \cdot 265$ & 0.065 & $0.28(0.02)$ & $2 \cdot 40$ \\
\hline $\mathrm{D}$ & $0 \cdot 77$ & $0 \cdot 14$ & $0.69(0.06)$ & $1 \cdot 80$ & 0.605 & 0.085 & $0.55(0.11)$ & $1 \cdot 60$ \\
\hline $\mathrm{E}$ & $0 \cdot 55$ & .0 .06 & $0.47(0.02)$ & $2 \cdot 40$ & $0 \cdot 46$ & $0 \cdot 025$ & $0.44(0.02)$ & $7 \cdot 20$ \\
\hline $\mathrm{F}_{0}$ & $0 \cdot 37$ & 0.05 & $0 \cdot 21(0 \cdot 02)$ & $0 \cdot 720$ & $0 \cdot 185$ & $0 \cdot 03$ & $0 \cdot 17(0 \cdot 02)$ & $4 \cdot 80$ \\
\hline $\mathrm{F}_{1}$ & $0 \cdot 33$ & 0.04 & $(0 \cdot 28-0 \cdot 20) \ddagger$ & $3 \cdot 60$ & $0 \cdot 215$ & $0 \cdot 02$ & $0 \cdot 19(0.02)$ & $4 \cdot 80$ \\
\hline $\mathrm{F}_{2}$ & $0 \cdot 35$ & $0 \cdot 16$ & $0.24(0.04)$ & $7 \cdot 20$ & $0 \cdot 205$ & 0.025 & $0 \cdot 19(0 \cdot 02)$ & $2 \cdot 88$ \\
\hline $\mathrm{F}_{3}$ & $0 \cdot 57$ & $0 \cdot 125$ & $0 \cdot 38(0 \cdot 04)$ & $4 \cdot 80$ & $0 \cdot 285$ & 0.025 & $0.27(0.02)$ & $3 \cdot 60$ \\
\hline
\end{tabular}

$*$ Determined from graphs; $\uparrow$ calculated from original data; $\ddagger$ recovery decreased with time material under load; $\S 1 \mathrm{MPa}$-sec $=10^{7}$ poise.

In order to simplify comparisons of the compliance components for a single material and between materials, $J_{0}, J_{R}, t / \eta$, and $R_{T}$ are plotted as bar graphs for the 1 min and $1 \mathrm{~h}$ samples in Figs 4 and 5. The viscous flow term is at the top of each bar for the total creep at 12 min under load. The magnitude of the viscous flow is time-dependent and can be related to the permanent deformation of a material. The numbers 1, 2 and 3 under the code letters indicate a heavy-, regular-, or light-bodied material. The 1-min creep compliance test showed that the average recovery, $R_{T}$, was less than the total elastic creep compliance, $J_{0}+J_{R}$. These data indicate that polymerization was continuing during the test, and the recovery decreased significantly with the length of time under load. This effect was not observed for the 1-h creep compliance values.

The creep compliance of the polysulphides generally decreased from the lightto heavy-bodied classes and the creep compliance values for the polyethers were lower than those for the silicones and polysulphides. The results of the rankings by the Scheffé test are shown in Fig. 6 for the 1-min and 1-h samples at $5 \mathrm{~s}, 1$ min and $6 \mathrm{~min}$. The underscoring indicates which materials were not statistically different at the $95 \%$ level of confidence. More overlapping of rankings occurred the longer the time for both the 1-min and 1-h samples. The 5-s measurements were related to the $\mathrm{J}_{0}$ values while the 1 - and 6 -min values indicate differences in $\mathrm{J}_{\mathrm{R}}$ and $\mathrm{t} / \eta$.

The 5-s values for the 1-min and 1-h samples showed that the light-bodied polysulphide (A) had the highest creep compliance followed by polysulphide (D) and the following groups: (1) polysulphide regular-bodied, silicone regular and in one instance 


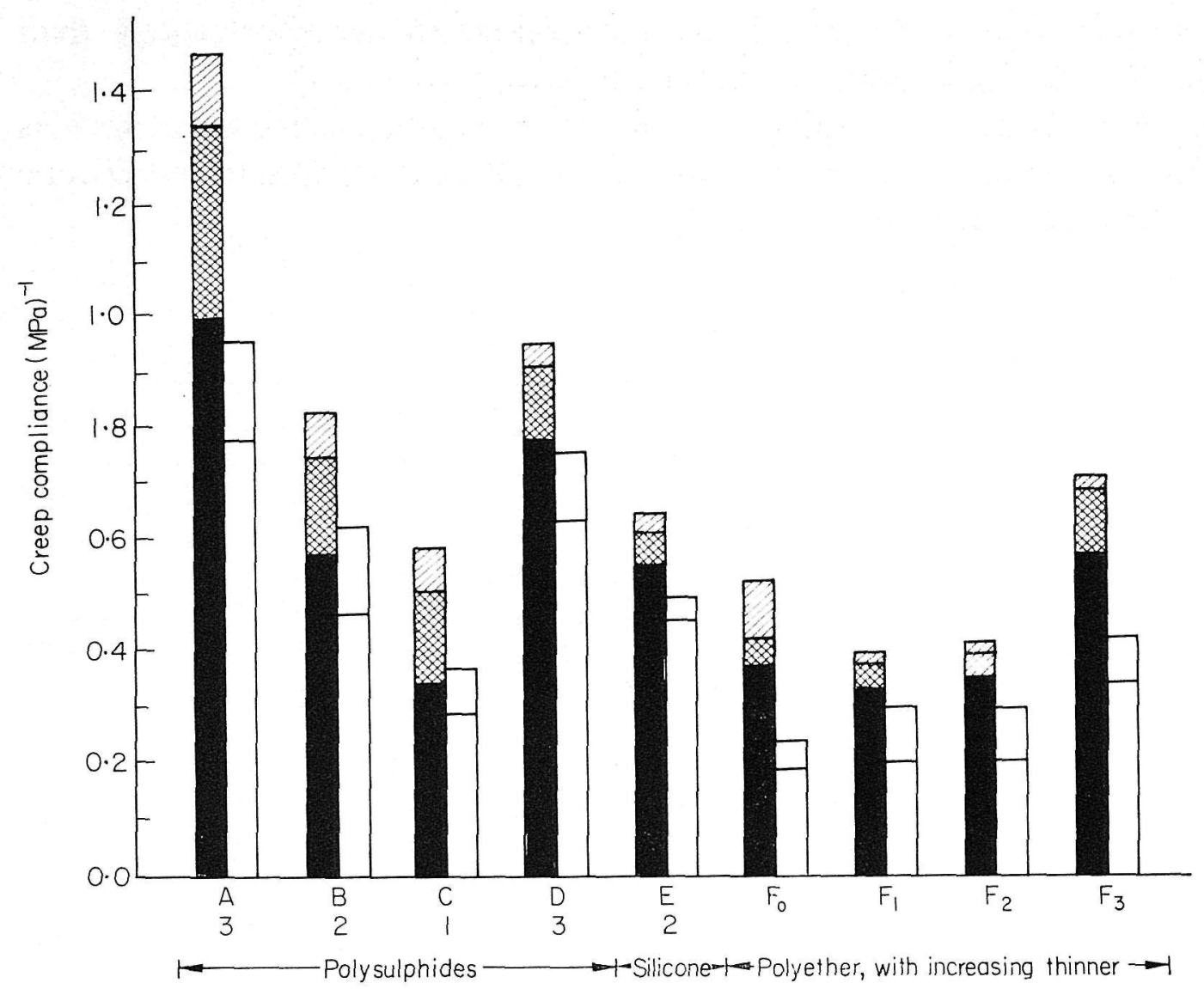

Fig. 4. Elastic, $J_{0}$, retarded elastic, $J_{R}$, viscous, $t / \eta$, and recovery, $R_{T}$, compliance for 1 -min samples of polysulphides, silicone, and polyether impression materials. Filled column, $\mathbf{J}_{0}$ (instantaneous); cross-hatched column, $\mathrm{J}_{\mathrm{R}}$ (retarded); hatched column, $t / \eta$ (viscous flow); open column, $\mathrm{R}_{\mathrm{T}}$ (recovery).

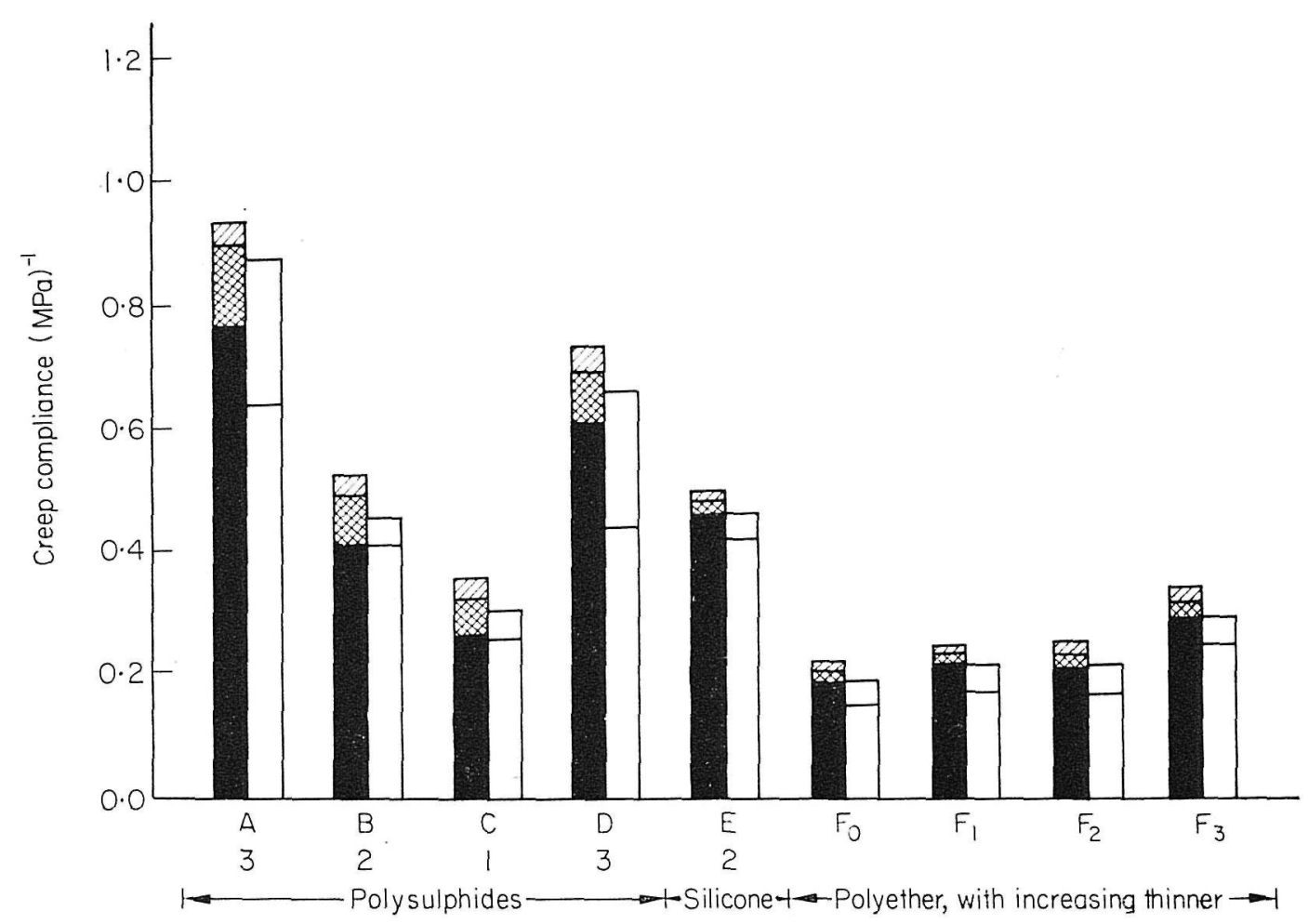

Fig. 5. Elastic, $J_{0}$, retarded elastic, $J_{R}$, viscous, $t / \eta$, and recovery, $R_{T}$, compliance for $1-h$ samples of polysulphides, silicone, and polyether impression materials. For key see Fig. 4. 
the highest diluted polyether, and (2) polysulphide heavy-bodied and the polyether undiluted and diluted 1:0.25 and 1:0.5. The 1- and 6-min values for the 1-min samples resulted in more overlapping of the rankings but with only $B$ and $F_{3}$ changing places. The 1- and 6-min values for the 1-h samples also resulted in more overlapping of the rankings with $\mathrm{B}$ and $\mathrm{E}$, and $\mathrm{C}$ and $\mathrm{F}_{3}$ changing places although the switching was not statistically significant.
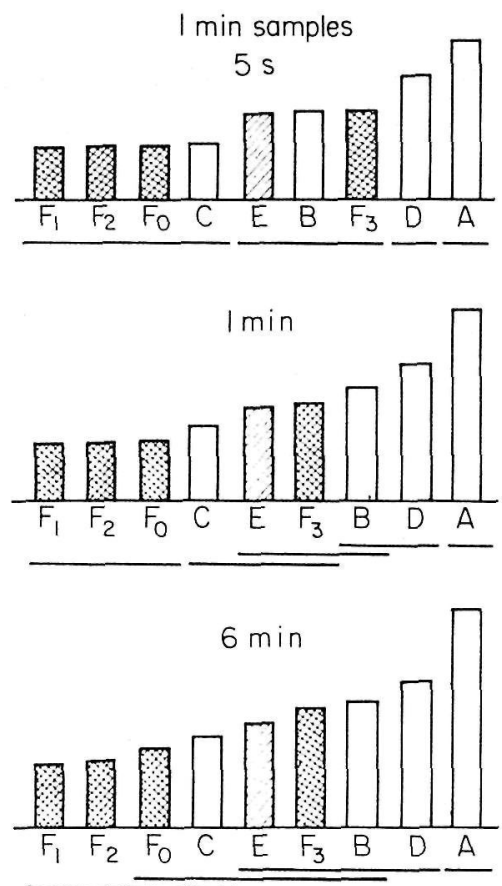

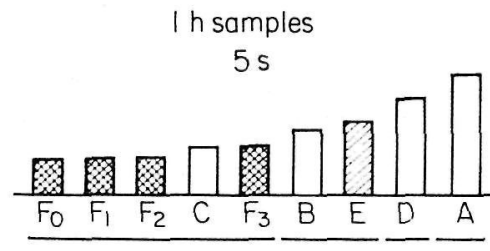

$1 \mathrm{~min}$

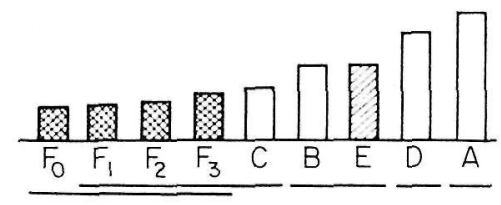

$6 \min$

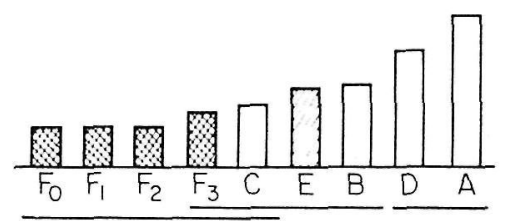

Fig. 6. Scheffé multiple comparisons of the creep compliance for $1-\mathrm{min}$ and 1-h samples at $5 \mathrm{~s}, 1 \mathrm{~min}$ and $6 \mathrm{~min}$.

\section{Discussion}

The creep compliance curves and the calculated values for the elastic, retarded elastic, and viscous components are of special value in evaluating the behaviour of elastic impression materials. $\mathrm{J}_{0}$ for the syringe $(\mathrm{A})$, and heavy body $(\mathrm{C})$ polysulphide showed that the elastic component decreases as the consistency increases; $J_{R}$ for the three consistencies did not vary greatly or regularly but $\eta$, the viscous component, increased as the consistency increased. After $1 \mathrm{~h} \mathrm{~J}_{0}$ and $\mathrm{J}_{\mathrm{R}}$ decreased for each consistency indicating continued polymerization; $\eta$ for the syringe and regular became approximately the same as for the heavy-body. The recovery for $\mathrm{A}-\mathrm{C}$ when tested at $1 \mathrm{~h}$ compared to $1 \mathrm{~min}$ after removal from the $37^{\circ} \mathrm{C}$ water bath were closer to $\mathrm{J}_{0}+\mathrm{J}_{\mathrm{R}}$, the total elastic compliance; these results again indicate polymerization was continuing after setting of the impression material.

The elastic compliance ranked polysulphide D between $\mathrm{A}$ and $\mathrm{B}$ although the viscous component ranked it between $\mathrm{B}$ and $\mathrm{C}$ which again suggests the compliance values characterize materials better than consistency values.

The low $\mathrm{J}_{0}$ values (Table 2 ) for the silicone and polyethers showed their greater stiffness than the polysulphides and the values for $R_{T}$ were nearly the same as the total elastic compliance, $\mathrm{J}_{0}+\mathrm{J}_{\mathrm{R}}$, indicating minimum permanent deformation on removal from undercut areas.

The compliance values for polyether diluted with thinner changed only slightly 
showing that the thinner can be used effectively to increase the working and setting times without serious degradation of the elastic behaviour of the set material. The Scheffé ranking, for example, on the 1 -min samples at $5 \mathrm{~s}$ placed $\mathrm{F}_{3}$ in the second group rather than the first group with $F_{0}, F_{1}$, and $F_{2}$. However, at $1 \mathrm{~h}$ the 5 -s value for $F_{3}$ was ranked in the same group as $F_{0}, F_{1}$ and $F_{2}$.

The Scheffé rankings for the 1-min and 1-h samples at $5 \mathrm{~s}, 1 \mathrm{~min}$ and $6 \mathrm{~min}$ showed no change in ordering although several changes occurred based on comparison of averages. A comparison of the Scheffé rankings for the 1-min and 1-h samples at comparable times showed a few changes in ordering, the principal change being that the most highly diluted polyether was no longer different from the others for the 1-h samples. The main effects of adding thinner were to allow easier mixing, to decrease the effective polymerization rate, to provide more working time, and to give a more flexible impression material.

\section{Acknowledgment}

This study was supported by Training Grant DE-00181 from the National Institute of Dental Research, Bethesda, Md.

\section{References}

Goldberg, A.J. (1974) Viscoelastic properties of silicone, polysulfide, and polyether impression materials. Journal of Dental Research, 53, 1033.

Guenther, W.C. (1964) Analysis of variance, p. 141. Prentice-Hall, Englewood Cliffs, N.J.

OGLesby, P.L. (1972) Viscoelastic behavior. In: Symposium on dental materials research (Ed by G. Dickson and J. Cassel). National Bureau of Standards Spec. Publ. 354, Government Printing Office, Washington, D.C.

Manuscript accepted 24 January 1977 
This document is a scanned copy of a printed document. No warranty is given about the accuracy of the copy. Users should refer to the original published version of the material. 